\title{
Serious Game Design: Presenting a New Generic Creative Reflection Framework
}

\author{
https://doi.org/10.3991/ijet.v15i19.15603
}

\author{
Fatima-Zohra El Arroum $\left({ }^{\bowtie}\right)$, Mostafa Hanoune, Youness Zidoun \\ Hassan II University of Casablanca, Casablanca, Morocco \\ f.elarroumegmail.com
}

\begin{abstract}
Serious games are transcending the way of teaching and learning nowadays. Since serious games balance playful and educational aspects, it constitutes a privileged learning method for the digital natives. However, they are ubiquitous in today's society and their stakes and assets remain largely fuzzy. This paper describes different models and frameworks for serious games design. Between theoretical and technical consideration, authors propose a new reflection model that aims to help pedagogues guiding their conception of serious games. This model is a result of a thematic synthesis analyzing more than 40 texts offering a three-layered model covering the simplest to the most advanced design. Three study cases are announced to be conducted by the end of this year in order to challenge and evaluate this new model.
\end{abstract}

Keywords - Serious game, serious game design, reflection model, generic models.

\section{Introduction}

As odd as it may seem, it has been proven that we can trace the origins of the phrase "Serious Game" dating from the Renaissance (fifteenth century). At the time, humor was used instead of games to convey serious concepts [1].

On a more contemporary scale, one of the first definitions of serious game has been formalized by Clark Abt in his book Serious Games [2]. The latter thinks that "games can be played seriously or simply, we are interested in serious games in the sense that these games have an explicit and thoughtful purpose and are not intended to be played primarily for amusement. to say that serious games are not or should not be entertaining ". Being part of the game project TEMPER [3], which is a computer simulation game used by army officers to study the "cold war" conflict on a global scale [3].This author proposes also some non-computer media games that can be used in scholar environments such as mathematics games or human sciences. The majority of definitions that followed [4][5] were influenced by Ben Sawyer's approach through his book Serious Games: Improving Public Policy through Game-based Learning and Simulation [6].Chen \& Michael stated that serious games are any games whose main purpose is not only to entertain [7]. One of the most famous definitions was Zyda's [5], thinking that serious games are "A mental contest, played with a computer in 
accordance with specific rules, that uses entertainment, to further government or corporate training, education, health, public policy, and strategic communication objectives". However, all of these definitions link the serious aspect of training or education to the video game industry. Nowadays, several names come to embed themselves in this definition trying to further expand the serious games spectrum of identity namely: Educational Games, Simulation-based learning, Virtual Reality, Edutainment, Digital Game-Based Learning, Immersive Learning Simulations, Persuasive Games, Synthetic Learning Environments.,.

Every actor (educator, learner, author, game designer) has his own vision and opinion of serious game according to his sector of origin, but still, there is a lack of guidance for serious game designing. Design tips are the most common form existing. Although they do not offer theoretical tools to help reflection, they all seem to follow a similar philosophy and remain rich of lessons in terms of video games creation.

To help thinking about the serious game design, authors are interested in these models of guidance to bring a new modeling framework that will treat in more detailed manner the complexity of the design as well as the analysis of serious games.

\section{Background}

Before going further, two important concepts strictly related to serious game must be identified. Design methodologies and creative thinking tools for serious game, are two kinds of theoretical tools aiming to facilitate game design. In terms of design methodologies, many models of video game's creation can be observed in the literature. Each model is based on different series of steps, like Crawford's approach [8], Bateman \& Boon [9] and the Adams approach [10].

\subsection{The ADDIE generic model}

Recurrences can be identified in all of previous models, which opened doors for generic models propositions like the ADDIE generic model [11]. More used as a theoretical framework for the implementation of educational curricula, this model is composed of five separate stages "Analysis", "Design", "Development", "Implementation" and "Evaluation". The analysis phase proposes to the instructor to identify precisely the educational objective as well as the target audience. The design phase makes it possible to establish the different stages of the educational program. The development phase ensures the creation of all the educational contents of the curriculum that will be tested with during the implementation phase. Finally, the evaluation phase verifies the relevance of the curriculum according to a formative evaluation method, which continues throughout the creation process, and a summative evaluation method that follows to test some aspects of the curriculum on a specific audience. 


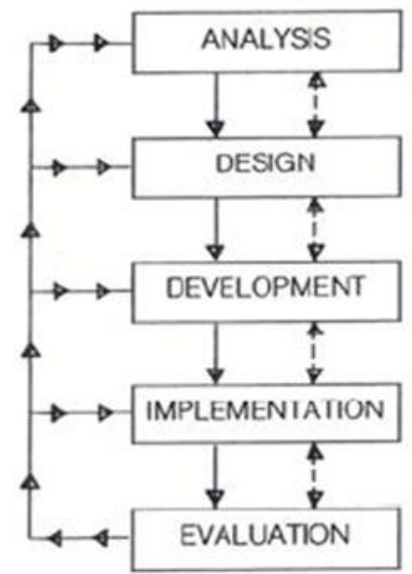

Fig. 1. The ADDIE generic model

As a result of an empirical practice of pedagogical engineering, this model is qualified generic because of its rarely concise and strict use. Thus, each pedagogue is free to propose his own variable number of "stage series" relying in part or totally on the five generic steps stopped by the ADDIE model.

\subsection{The ICE generic model}

The ICE model is part of the continuity of the ADDIE model. It synthesizes several other models specific to the creation of video games according to three major stages namely: Imagine, Create, Evaluate [12].

- Imagine: In this phase, a game concept is invented. This stage relies entirely on the use of theoretical tools.

- Create: The prototype is made at this level to test the relevance of the game concept throughout the use of technical tools.

- Evaluate: The prototype is evaluated on a target audience. The evaluation criteria can be chosen to match each project objectives.

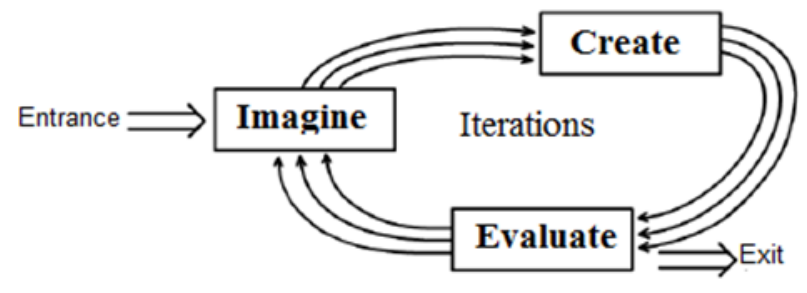

Fig. 2. The ICE generic model

One of the most important aspects that should be considered is the notion of iterative cycles. This model is entirely based on an iterative cycle that begins with an 
imagine step and complete after an evaluate one as represented previously in figure 2 above.

\subsection{The game design models}

Several studies suggest that the concepts related to game design would be perfectly applicable to serious game design at least on the technical side. Leaving the theoretical one more open to reflection because of the serious aspect that must mark every dimension of the game [4].

The multidimensional typology of games proposed by Elverdam \& Aarseth is the perfect example of the theoretical tool for helping creative thinking [13]. It details in a very specific way 16 different aspects of a game design, starting with the representation of the space that can be either real or virtual to the way of managing the current states of the game and throughout the objectives and the number of players. As much interesting, the tokens theory proposed by Rollings \& Morris [14] divides each element of the game into smaller conceptual unit's which called "Tokens". A great hierarchy is then possible to be modeled since one token can regroup multiple other tokens. More adapted to people familiar with computer concepts, the two models proposed by Lecky-Thompson [15] and Dormans [16] represent another approach to reflection. The Object-Oriented Design Game by Thomson divides each element of the game not into tokens but into "objects" that enjoy the same attributes and properties of the computer programming paradigm. Another distinction of this approach is that the objects join both the information about the state of the game and the ability to apply the rules.

\subsection{Research purpose}

The main purpose of this study was to contribute in the field of teaching and learning by designing a framework for thinking about the integration of serious games. The three research questions guiding this study are:

- What is the understanding of serious games in education and what frameworks have already been developed?

- What differentiates learning with serious games from the traditional e-learning?

- What should an educator think about when integrating serious games into the curriculum?

\section{$3 \quad$ Methodology}

In order to address our research questions and to achieve the realization of our serious game integration framework, a thematic synthesis has been adopted [17].

Much different from a literature review where the goal is simply summarizing existing research and making its important points available in a single document, the thematic synthesis can be used to bring different research together [18] which make it 
very suitable for multidisciplinary data analysis, covering all paradigms to offer an understanding of their activities [19]. This study involves the investigation of different methods in the technological/educational areas, ICT integration in education, computer science, educational frameworks, etc.

In order to conceive a new serious game integration model, authors adopted a thematic synthesis which allowed to prioritize the transversal data collected previously through a corpus analysis of more than 40 texts, including terms such as "game design", "serious game", "design methodologies", "creative thinking". Inspired by the method in Ref [17], the researchers proceeded in three steps explained below:

- First, authors identified the different themes and fields of the research from the studies collected before. Subsequently, they transformed these results into a transverse metric. At this stage the codification was rather descriptive but still similar to the texts previously contained in the studies reported on the corpus. Next, support software for qualitative and combined research methods was used.

- The next step consisted on organizing the previously identified thematic codes into descriptive themes in order to "develop and articulate relationships between the themes and associate conceptually similar themes with one another"[18]

- Last, analytical themes were generated. At this stage, the synthesis has widely crossed the limits of the initial texts content of the original studies proposing new conceptualizations.

\section{$4 \quad$ Results}

The thematic synthesis allowed us to identify new associations between the different concepts that we studied and considered as an entry into the new integration framework of the serious game. Several qualitative considerations have been retained, which allowed us to propose a new synthetic model of serious game design that comes in three superimposed modeling that describe different levels of vulgarization of serious game design. The first layer of the model highlights the close link between the learning content and the skills to be acquired. In a conceptualization of educational content, several skills are targeted in order to make them learnable to the players at the end of the learning path as shown in figure 3 below. 


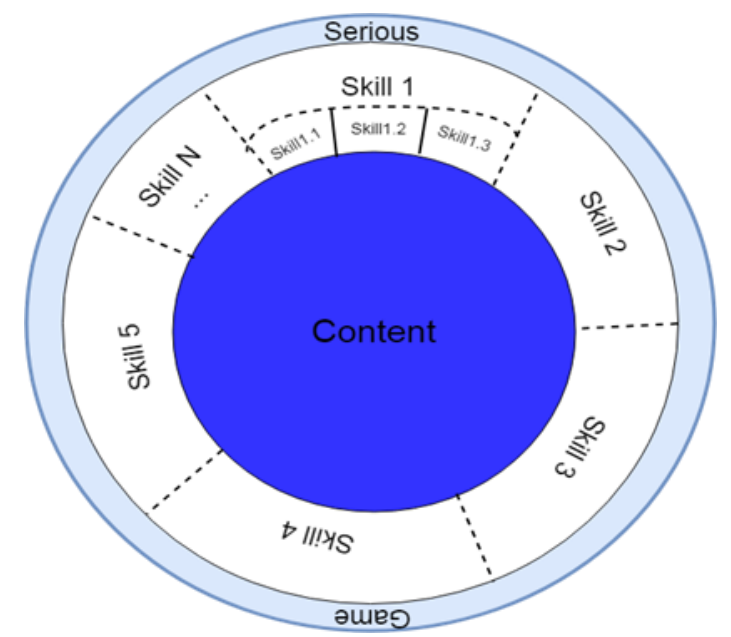

Fig. 3. Link model between learning content and the relative skills

The second layer extends as simplified reflection of a basic gamification design. As it appears in figure 4 below and once the relative competences listed, a respective assessment in a simple form of a quiz is associated and thus makes it possible to act on the attributes of the game like the time or the score (two concepts strongly linked to the gaming world). The reflection can start inside out or vice versa allowing the instructors to build the knowledge and then transpose it to a simple game play that connects the two frontiers of serious game learning. The game thus offers two basic attributes on which the quiz results act relatively allowing the player to progress further in the game. The model exposes two of the most historic attributes of all game plays namely the score and the time.

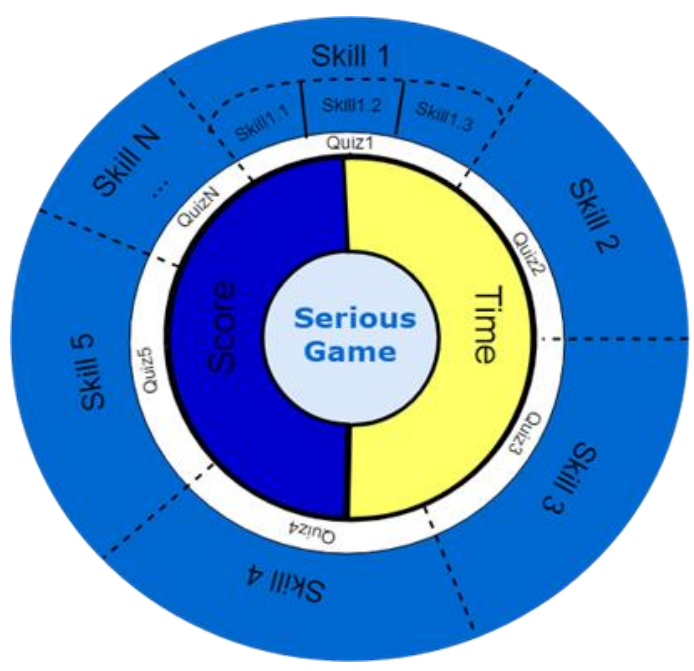

Fig. 4. Simplified game-based design model 
The third layer of the model addresses the more advanced types of serious games by dealing in more detail with the game-related aspects. Each skill is tied to a specific evaluation that is associated in part with one or more attributes of the game allowing its validation. The figure 5 shows how these relations are conceptualized and define the sensitivity in which such associations has to be made in order to achieve an efficient learning through the gaming process.

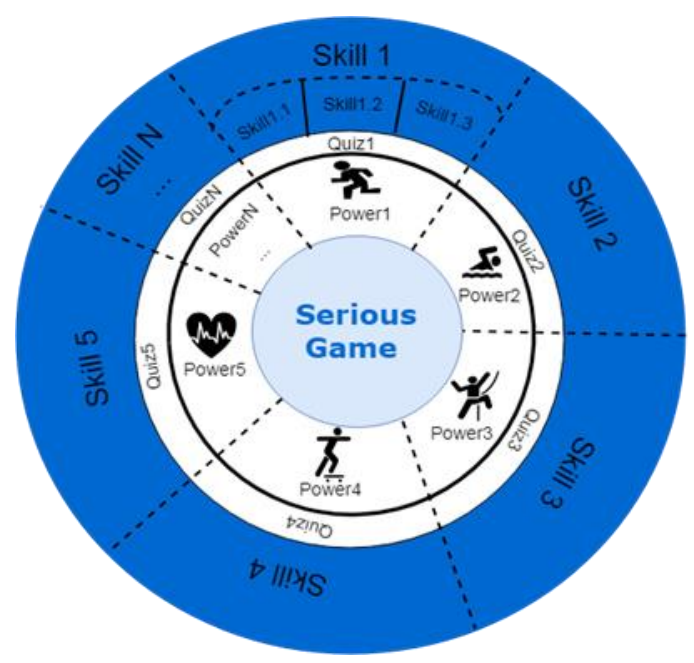

Fig. 5. Advanced game-based design model

The diagram below shows how these three sublayers constitute a single generic reflection model to group the series of considerations from both the world of gaming and pedagogy to create an efficient learning synergy. Figure 6 below is a layering of the three previous models.

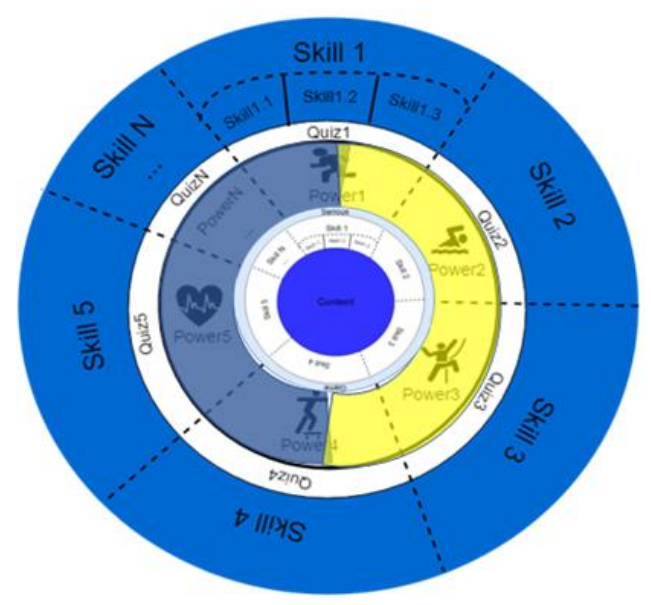

Fig. 6. The generic game-based design model 


\section{Conclusion}

Several methodologies for designing and creating serious games can be observed. Although most are based on well-defined steps, many recurrences can be found which allowed the authors to propose a generic model of reflection around serious gaming. The model presented in this paper brings together the various considerations related to pedagogy and videogames to assist the instructors in their reflection and thus guide them throughout their design. Future work will be driven in the same scope of helping instructors for designing serious games. A series of study cases will be conducted to challenge and evaluate this generic model in order to further improve it. Three studies will be launched by the end of the year. The first will be devoted to learning HTML through the application of the new model of reflection in order to transcend the way of teaching this type of educational content by serious gaming. The second case will be interested in applying this new model proposed for the realization of a game for OSI model vulgarization. The third study case will explore the application of deep learning into the generic model. The results will offer a new conceptualization of the model that authors hope will constitute a new reference in the world of serious games.

\section{References}

[1] Manning, J. (2004). The Emblem. Reaktion Books.

[2] Abt, C. C. (1970). Serious Games. Viking Press.

[3] Abt, C. C., Hodder, J. C., \& O'Sullivan, T. C. J. (1965). TEMPER: The Theory of the Model. Raytheon.

[4] Alvarez, J. (2007, December 17). Du jeu vidéo au serious game, approches culturelle, pragmatique et formelle (PhD Thesis). Toulouse, France: Université de Toulouse.

[5] Zyda, M. (2005). From Visual Simulation to Virtual Reality to Games. Computer, 38(9), 25-32. https://doi.org/10.1109/mc.2005.297

[6] Sawyer, B., \& Rejeski, D. (2002). Serious Games: Improving Public Policy Through Game-based Learning and Simulation. Woodrow Wilson International Center for Scholars.

[7] Chen, J., \& Ringel, M. (2001). Can Advergaming be the Future of Interactive Advertising? $<$ kpe>.

[8] Crawford, C. (1982). The Art of Computer Game Design: Reflections of A Master Game Designer. Osborne/McGraw-Hill,U.S.

[9] Bateman, C., \& Boon, R. (2005). 21st Century Game Design (1er ed.). Charles River Media.

[10] Adams, E. (2009). Fundamentals of Game Design (2 ed.). New Riders Press.

[11] Molenda, M. (2003). In Search of the Elusive ADDIE Model. Performance Improvement, 42(5). Retrieved from http://www.eric.ed.gov/ERICWebPortal/detail?accno=EJ676523

[12] Djaouti, D. (2011). Serious Game Design: considérations théoriques et techniques sur la création de jeux vidéo à vocation utilitaire (Doctoral dissertation, Université de Toulouse, Université Toulouse III-Paul Sabatier). https://doi.org/10.3934/dcdss.2011.4.761

[13] Elverdam, C., \& Aarseth, E. (2007). Game Classification and Game Design: Construction Through Critical Analysis. Games and Culture, 2(1), 3-22. https://doi.org/10.1177/155541 $\underline{2006286892}$ 
[14] Rollings, A., \& Morris, D. (2003). Game Architecture and Design: A New Edition. New Riders Games.

[15] Lecky-Thompson, G. W. (2007). Video Game Design Revealed (1er ed.). Cengage Learning.

[16] Dormans, J. (2009). Machinations: Elemental Feedback Structures for Game Design. In GAME-ON-NA 2009: 5th International North American Conference on Intelligent Games and Simulation. Presented at the GAME-ON-NA 2009: 5th International North American Conference on Intelligent Games and Simulation, Atlanta, USA. Retrieved from http://www.jorisdormans.nl/article.php?ref=machinations

[17] Thomas, J., Harden, A., \& Newmark, M. (2012). Synthesis: Combining results systematically and appropriately. In D. Hough, S. Oliver, \& T. James (Eds.), An introduction to systematic reviews (pp. 179-226). London: SAGE Publications.

[18] Thomas, J., \& Harden, A. (2008). Methods for the thematic synthesis of qualitative research in systematic reviews. Bmc Medical Research Methodology, 8(45). https://doi. org/10.1186/1471-2288-8-45

[19] Boyatzis, R. E. (1998). Transforming qualitative information: Thematic analysis and code development. sage.

\section{$7 \quad$ Authors}

Fatima-Zohra El Arroum is a PhD candidate at the Faculty of Sciences Ben M`Sik, Information Treatment and Modeling Laboratory, Hassan II University of Casablanca, Morocco. Her research fields are Serious games, frameworks, educational modeling and systems engineering.

Mosatafa Hanoune is a Professor of higher education at the Faculty of Sciences Ben M`Sik, Information Treatment and Modeling Laboratory, Hassan II University of Casablanca, Morocco. His research fields are frameworks, educational modeling and systems engineering.

Youness Zidoun is a $\mathrm{PhD}$ holder from the Faculty of Sciences Ben M'Sik, Information Processing Laboratory, Hassan II University of Casablanca, Morocco. His research fields are m-learning frameworks, educational modeling and systems engineering.

Article submitted 2020-04-21. Resubmitted 2020-05-27. Final acceptance 2020-05-28. Final version published as submitted by the authors. 